BOOK REVIEW

\title{
Transparency unveiled
}

\author{
BARBARA MINTZES
}

\begin{abstract}
Katherine Fierlbeck, Janice Graham and Matthew Herder, editors. Transparency, Power, and Influence in the Pharmaceutical Industry: Policy Gain or Confidence Game? University of Toronto Press, 2021 June, Paperback: \$26.96; E-book: \$26.96, 304 pgs, ISBN: 9781487529048.
\end{abstract}

From a public interest perspective, the most important policy shift in the regulation of medicines in the 21st century is improved transparency. Until recently, the scientific evidence that companies provided to regulators to support approval of medicines for marketing was largely considered "confidential business information", kept secret from researchers, clinicians, patients, and the public. This confidential information has included full reports of clinical trials testing treatment effectiveness. Policy shifts to open this body of scientific evidence to public scrutiny are a major advance, allowing independent researchers to re-analyse trials based on full unfiltered reports. Several of these reanalyses have led to profound shifts in the understanding of benefits and harmful effects of medicines. A second major win for public interests has been in uncovering not just the science but also the financial links between pharmaceutical companies and clinicians, through legally mandated company reporting in the United States (US) and in several European countries. Other countries, including the UK, are considering similar legislation [1], and self-regulatory industry reporting systems exist throughout the European Union and in Australia and the UK.

Transparency, Power, and Influence in the Pharmaceutical Industry: Policy Gain or Confidence Game?, edited by Katherine Fierlbeck, Janice Graham and Matthew Herder, is

Authors: Barbara Mintzes (Barbara.mintzes@sydney.edu.au), Charles Perkins Centre and School of Pharmacy, Faculty of Medicine and Health, The University of Sydney, Sydney, NSW, 2006 AUSTRALIA.

To cite: Mintzes B. Transparency unveiled. Indian J Med Ethics. Published online first on February 28, 2022. DOI: 10.20529/IJME.2022.018

Manuscript Editor: Sanjay A Pai

Copyright and license

(C) Indian Journal of Medical Ethics 2022:Open Access and Distributed under the Creative Commons license CC BY-NC-ND 4.0, which permits only non-commercial and non-modified sharing in any medium, provided the original author(s) and source are credited. the first in-depth analysis of this profound policy shift from secrecy to public information access. The authors examine the conditions that have led to improved transparency and evaluate the progress made in holding the industry to account. Secondly, they ask whether these changes matter: have they improved public safety and corporate accountability or are they largely "symbolic and toothless"?

Ultimately Fierlbeck et al argue that public information access is important but is no panacea. Hard fought gains can be lost again, as occurred temporarily when the European Medicines Agency (EMA) was challenged in court for making full clinical trial reports publicly available. Health Canada initially released data only if researchers signed a confidentiality agreement, preventing the information from being shared. Transparency gains only became meaningful after a successful legal challenge of this confidentiality requirement. These examples highlight the need for ongoing policy advocacy. Fierlbeck warns that, "Like weight loss, immediate gratification is unlikely, and long-term maintenance essential." (p 46)

The importance of long-term advocacy is highlighted in three analyses of policy changes leading to greater transparency in the European Union (EU), the US, and Canada. In chapter 3, Davis, Mulinari and Jefferson describe the key role of an advocacy coalition, the Medicines in Europe Forum (MiEF), in shifting the European Medicines Agency (EMA) approach to transparency. MiEF united patients, health professionals, independent information providers, researchers and health insurance providers in advocacy for policy change [2]. The AllTrials Open Data campaign also helped to "mainstream" arguments around data transparency, including through a popular Ted Talk by Ben Goldacre [3]. As Davis and colleagues describe in this chapter, in 2007, the EMA refused to release Clinical Study Reports (CSRs) and protocols for 15 trials of obesity drugs to researchers at the Nordic Cochrane Centre. On appeal to the European Ombudsman, this decision was reversed in 2010, and the Ombudsman's judgment charged the EMA with "maladministration" in failing to make these reports publicly accessible. CSRs are the full reports of clinical trials that companies submit to regulators, often over 1000 pages in length, with much greater detail on methods and results than published reports.

Following the Ombudsman's ruling, the EMA dramatically 
shifted its policy, announcing proactive disclosure of CSRs for all new drugs. This policy was subjected to legal challenges by two pharmaceutical companies but was eventually upheld by the European Court of Justice, and was also enshrined in new European Clinical Trials regulations enacted in 2016.

The US Food and Drug Administration (FDA) has a long history of transparency legislation, dating from the 1966 US Freedom of Information Act (chap 4). The FDA initially defined information access narrowly, for example in 1970 refusing a request to release clinical trial reports for birth control pills to women's health activists within the context of congressional hearings on the pill's safety. The Watergate scandal led to political pressure for greater openness in government, including 1974 amendments to the Freedom of Information Act. For many years, the FDA released much more information than other regulators, including posting detailed reviewers' reports for drugs approved from 1997 onwards on its website and holding all advisory committee meetings in public, with full public access to background materials and transcripts. However, the FDA does not release clinical study reports (CSRs). And it provides no public information on nonapprovals, unlike the EMA and Health Canada.

A comparison of the US and Canada highlights the much more closed regulatory environment in Canada, with advisory committee meetings held in private, and only limited information on regulatory decision-making released at approval in Summary Basis of Decision documents that were introduced in 2005 (chap 4). A key window of opportunity paved the way for Health Canada's shift from "laggard" to "leader" in transparency policy: the introduction of legislation to expand Health Canada's regulatory role in safety oversight (Vanessa's Law) in 2014 (chap 5). This draft legislation was amended during parliamentary review to also include transparency provisions. Health Canada initially defined information access narrowly, requiring researchers to sign confidentiality agreements to access CSRs. This requirement was struck down in 2018 through a legal challenge by a US researcher, Peter Doshi, based on the Canadian Charter of Rights and Freedom. As a result, Health Canada began to release CSRs pro-actively, becoming the most transparent regulatory agency globally in terms of public access to CSRs.

Despite its leadership role in public access to CSRs, Health Canada has retained a closed approach in communicating publicly on regulatory decision-making. Joel Lexchin examines the information communicated on regulation of clinical trials, drug approvals, drug safety and drug promotion (chap 7). Information gaps largely outweigh access. For example, postmarket safety monitoring remains largely closed, with only summary safety reports released and little information on decision-making publicly available. Health Canada mainly delegates oversight of pharmaceutical promotion to multistakeholder and self-regulatory bodies, with no information on its website on the rulings of these organisations and minimal information on its own regulatory actions on drug promotion.
As these overviews of three regulatory agencies attest, there has been a sea change in public access to CSRs but access to other scientific and regulatory information remains piecemeal. Has access to CSRs made a difference to clinical care? Nav Persaud examines four situations in which reanalyses of trials led to opposing conclusions from initial published reports: antidepressants for adolescent depression; oseltamivir for flu complications; doxylaminepyrodixine for nausea and vomiting of pregnancy; and longacting opioids for chronic non-palliative pain (chap 6). In all four cases, full trial data showed that treatments were more harmful than helpful either due to lack of effectiveness, safety concerns, or both. However, these re-analyses made little difference to prescribing rates. Persaud highlights several interwoven reasons, including entrenched clinical practices, skepticism about new information, framing of the re-analyses as "controversial", dismissal of re-analyses of old studies as "old news", and countervailing effects of industry marketing and promotion. These examples provide a note of warning that improved transparency does not necessarily lead to better public health.

Another case study examines the opposing pressures of trial participants' rights to privacy and public information access rights in rare disease drug trials (chap 9). This "false dichotomy" ignores technical advances to maintaining anonymity and presents data sharing as counter to patient interests. In fact, rare disease patients may especially benefit from data sharing, due to the seriousness of their medical conditions and the need to avoid all unnecessary research duplication when potential trial participant numbers are so small.

Two theoretical analyses examine why transparency does not necessarily change practice and why the fight over public access to scientific information has been so tough. Katherine Fierlbeck defines transparency as "... not a simple policy endpoint, but rather a tool that can be employed in a larger contest over policy and influence." (p 51). Effective policy advocacy needs to consider underlying power dynamics, and the way that powerful actors frame discourse. For example, concepts may be redefined in a way that neutralises their significance. She cites the way that conflicts of interest have been widely redefined, including "intellectual conflicts of interest", creating a distraction from the power dynamics of widespread industry financing of health professionals. These power dynamics are highlighted again by Marc-André Gagnon in his discussion of the political economy of influence and ghost management in the pharmaceutical sector (chap 8). He argues that pharmaceutical companies need to produce "the social determinants of value", influencing and shaping habits of thought in the community in line with their interests, in order to maximise profitability. This political economy of influence is often hidden, with examples including pharmaceutical companies' use of public relations companies to create "activists" in favour of a company 
agenda. Identifying and mapping how influence occurs is key to any challenge and public access to science combats corporate strategies that focus on "selectively producing ignorance through non-disclosure of clinical trial data".(p 176)

As the authors of Transparency, Power, and Influence in the Pharmaceutical Industry highlight, unveiling corporate strategies of social control and the scientific evidence underpinning the use of medicines are "necessary but not sufficient" steps towards finding solutions to undue corporate bias in medical research and regulatory policy. This book provides a detailed historical record of policy shifts that have brought previously secret scientific evidence into the public domain. As a detailed analysis of lessons learned in the fight for transparency, it is a must read for public health activists.
Funding: None declared

Competing interests: Barbara Mintzes is an expert witness for Health Canada in a legal case involving marketing of an unapproved drug product.

\section{References}

1. Macleod S. A sunshine payment act for the UK. BMJ 2021;374:n1900 doi:10.1136/bmj.n1900

2. Prescrire International. A Global Network: Medicines in Europe Forum. 2016 Nov [cited 2022 Jan 4]. Available from: https:// english.prescrire.org/en/82/177/0/312/About.aspx..

3. Goldacre B. What doctors don't know about the drugs they prescribe. Youtube. 2012 Jun [cited 2022 Jan 4]. Available from: https://www.ted.com/talks

ben_goldacre_what_doctors_don_t_know_about_the_drugs_they prescribe 